Tihomir Brajović*

Filološki fakultet

Univerzitet u Beogradu
UDK: 821.163.41.09-1:808.1

DOI: $10.19090 /$ gff.2021.1.15-29

Originalni naučni rad

\title{
FUNKCIJA ELIPSE, ALUZIJE I IRONIJE U TUMAČENJU LIRIKE
}

Predmet ovog naučnog rada predstavlja retorska strategija verbalnog uskraćivanja ili izostavljanja u lirskom pesništvu, s osvrtom na estetsku funkciju jezika i svojstva sažetosti, konotativnosti i polisemičnosti lirike kao žanra. Autor rada elipsu razmatra kao retorsku figuru i/ili poetički prosede, teorijski elaborišući njenu funkciju intrinsičnog uskraćivanja u lirskoj pesmi; pri tome je pesma „Epitaf” M. Nastasijevića poslužila kao eksplikativni primer. Aluzija je, s druge strane, shvaćena kao figura/prosede ekstrinsičnog verbalnog uskraćivanja, a „Nova radost” A. Ristovića uzeta je kao eksplikativni primer. Naposletku, ironija je tretirana kao figura/postupak intrinsično-ekstrinsičnog verbalnog uskraćivanja, s tim što je „Livada” S. Raičkovića kao eksplikativni primer. Završni deo rada posvećen je interpretativnim konsekvencama ovako uspostavljenog razumevanja funkcije elipse, aluzije i ironije u lirskoj pesmi.

Ključne reči: poetika, retorika, elipsa, aluzija, ironija, intrinsičnost, ekstrinstičnost, kontekst

Iako možda na prvi pogled ne izgleda tako, uskraćivanje predstavlja moćno sredstvo književnog izražavanja. Reč je, naravno, o posrednom, implicitnom retorskom delovanju koje počiva na efektima odsustva i sugestije, a putem sadejstva onoga što je rečeno i onoga što je prećutano. To združeno dejstvo se, valja kazati, na neki način pojavljuje čak i u eksplicitnom kazivanju, uzorno datom $u$ komunikativno-informativnoj upotrebi jezika, preovlađujućoj izvan književnosti, u okviru koje upotreba svojevrsnih „nemih“ znakova, poput neverbalnih ili paralingvističkih komponenata govora (gestovi, pokreti, mimika), ponekad može da saopšti više nego što je moguće i pretpostaviti (vidi Petković, 2003: 10-11).

Književno, tačnije: beletrističko kazivanje ima, međutim, i sebi svojstven „nemi““ diskurs, koji u izvesnom smislu dejstvuje uporedo s neposrednim, verbalno uobličenim govorom. U tom slučaju moguće je govoriti o svojevrsnoj retorici prećutkivanja, odnosno o uticaju na čitalačko razumevanje koje se u prvom redu ostvaruje verbalnim manjkom i izostavljanjem, odnosno njegovom kontekstualno

*tbrajo1@gmail.com 
uslovljenom semantizacijom. Ono što nije kazano u književnosti, drugim rečima, možda da bude i te kako značajno, katakad i presudno za razumevanje, zahvaljujući posebnom ustrojstvu verbalizovanih sadržaja. Tako govor i ćutanje postaju dva retorska lica istog, književnog saopštavanja i obraćanja.

Prethodno rečeno posebno, čini se, važi u polju lirskog modusa, po definiciji naklonjenog sažimanju, zgušnjavanju, komprimovanju. Onda kad se o lirskoj pesmi govori kao o „kratkoj” beletrističkoj formi, pri tome se ne misli samo na njen verbalni opseg, nego i na ono što je uzročno-posledično povezano s njim, a što potiče upravo od pomenute izražajne ,„skrtosti” (vidi npr Staiger, 1963: 25; Užarević, 1991: 40-41; Mendel, 1998: 80; Wolf, 2005: 24-25), potrebe za drugačije ustrojenim kazivanjem, koje umesto opširnosti teži jezgrovitosti i njenoj karakteristično izdašnoj, disperzivnoj proizvodnji značenja, estetskom fenomenu koji se - zavisno od pristupa, metoda, shvatanja, „škole” i krajnjeg pojmovnog dometa - teorijski imenuje kao polisemija, opalizacija, diseminacija, itd.

Reč je, naravno, o generičkom svojstvu književnog izraza u celini, onome što je u formalističko-strukturalističkoj tradiciji takođe imenovano i kao estetska funkcija jezika, ali je - o tome postoji širok konsenzus - uzorno manifestovano baš u lirskom pesništvu i njegovim retorički bogatim potencijalima, po pravilu okrenutim konotativnim, asocijativno razuđenim mogućnostima označavanja nauštrb denotativnih, neposredno referentnih značenja. „Manje je više” - ovaj poznati paradoks možda nigde ne pristaje tako dobro kao u lirici i s njom povezanim načinima produkcije i recepcije. Ne kazati sve ono što bi inače podrazumevala komunikativno usmerena informativnost pragmatične vrste, to $u$ lirskom pevanju prerasta u distinktivno obeležje, manir, opsesiju, i u njenu dominantnu crtu koja zahteva posebne interpretativne procedure.

Nema sumnje da je figura elipse, odnosno eliptičnost kao pesnički postupak na prvom mestu u razmišljanju o ovakvoj mogućnosti lirskog izražavanja. U užem značenju reči elipsa se ostvaruje sintaksičkim sažimanjem koje zahvaljujući verbalnom manjku otvara više od jedne verovatne mogućnosti nadomešćenja, a iz toga onda nastaje semantička pluralnost ili mogući „višak” značenja. Slikovito kazano, ono što čini umeće eliptičnog kazivanja jeste značenjsko „oblikovanje” netransparentnog, „odsutnog” sadržaja pomoću transparentnoga, onoga čime je to što nije kazano u neku ruku „obrubljeno” i tako zapravo nagovešteno, ako već nije sasvim determinisano. Stoga eliptičnost takoreći po pravilu vodi refleksivnosti. Jer ako je elipsa „oblikovana kao jezički rub koji seže izvan sebe, samo da bi se vratio sebi samom, onda je mišljenje ono što se pojavljuje izvan njega, tako da bi poezija mogla da bude delikatni događaj mišljenja" (Allen, 2007: 206). 
Momčilo Nastasijević je verovatno prvi među srpskim pesnicima kojeg ćemo se prisetiti kad govorimo o elipsi i eliptičnosti. Čuvena je enigmatičnost njegovog pesničkog stila, koja znatnim delom potiče upravo od eliptičnog sažimanja izraza. Od brojnih pesama za kojima bi se moglo posegnuti za ovu priliku biramo onu s naslovom „Epitaf”:

Plamen, - spržiti gde lek.

Mač, - odsecati glave gde kob.

Melem neprebolu.

Stamen bršljanu deblo, vekovati gde vek.

Zloduh zlu, dobroti verni rob;

rođaju žrtva, žetvi klas;

pečali, - sebi, grob i spas.

Kao što se zna, epitaf je nadgrobni natpis, obično uklesivan u kamenu, što život onoga kome je posvećen sažima do najbitnijih momenata. Valja, međutim, imati $u$ vidu zapažanje, oslonjeno na etimologiju i istoriju ovog osobeno pragmatičnog žanra, da je „,neposredno značenje njegovog pojma lokacija, a tek potom natpis [natpis na grobu]", zbog čega se čini umesnom teorijska opaska o tome da je epitaf svojim duhom zapravo „pogrebni epigram” (Newstok 2009: 46). Etiološki uslovljena pregnantost i eliptičnost su, prema tome, conditio sine qua non epitafskog izražavanja. Taj posthumni epigram- u onom smislu koji ima u vidu De Man, podsećajući na Vordsvortove Essays Upon Epitaphs - s druge strane može da bude shvaćen i kao uzoran primer prosopopeje, figure/postupka koja je u novije vreme tretirana u smislu jednog od suštinskih generatora lirskog dočaravanja (De Man, 1984: 77).

U svom lirskom „Epitafu” Nastasijević, autor majstorskih „Reči u kamenu", pesničkog ciklusa koji već svojim nazivom sugeriše metaforičnu „isklesanost" izraza, toj sugestiji naslovom dodaje i onu koja istim naslovnim označiteljem čitaocu stavlja do znanja da pesmom označeno predstavlja, prozopopeično izraženu, sumu ljudske egzistencije. U duhu pomenute sugestije lirski subjekat ovaj lirski epitaf eliptično „kleše” rečima nad sopstvenim životom, tražeći pri tome njegov sažeti smisao na dva načina.

Najpre, na mikrostrukturnom nivou, uočljivo je izostavljanje glagolskih reči, pre svega onih bazičnih, koje se odnose na samo postojanje i delovanje subjekta ([je]sam [bio]), a tamo gde ih ima u pitanju su infinitivni oblici (,spržiti”, 
„odsecati”, „vekovati”), delatno neaktivni, da tako kažemo. Isto važi i za i odstranjivanje zamenica, kojih zapravo uopšte nema, izuzev na samom završetku (,sebi”), gde je to bilo neizbežno. Apsolutna prevlast imeničkih reči i relacija (,zloduh zlu”, „rođaju žrtva” i sl) vodi, čini se, prema svedenosti na ono što je personalno supstantivno, bitno, baš kao što izraziti manjak zamenica i glagola doprinosi utisku suspenzije okazionalnog i promenljivog.

Drugi, interpretativno značajniji vid eliptičnog oblikovanja lirskog izraza u Nastasijevićevom „Epitafu” tiče se sažimanja u ravni ukupne konstrukcije, odnosno strukture pesme. Reč je zapravo o sadejstvu literarnih konvencija i mimikrijskog obličja teksta, odnosno o poetičkoj interferenciji poslovične lirske sažetosti i epitafske pregnantnosti. Ma koliko bio kratak, epitafski tekst u najvećem broju slučajeva podrazumeva, naime, sintaksičko-semantičku povezanost koja tendira sažetoj hipotaksičnosti pragmatične komunikacije, dok pesničke formulacije nisu obavezne uobičajenim, praktično komunikativnim pretpostavkama i zato neretko inkliniraju parataksičnom ustrojstvu kazivanja, oslobođenom transparentnih sintaksičko-semantičkih veza.

Stoga neće biti netačno ako kažemo da funkcionalno združena eliptičnost predstavlja strukturno načelo Nastasijevićeve pesme, jednako razaznatljivo u naslovu i samim stihovima. Elipsa je neiskazani i neimenovani, verbalno odsutni centar oko kojega ovde kruže reči i stihovi, semantički „titrajući” između „kamene” solidnosti kao epitafskog otiska i egzistencijalne (ne)postojanosti kao poetski „okamenjene”, eliptične bïlosti. Neverbalizovani „sadržaj” te strukturne elipse ovde je, pri tome, sam subjekt epitafa/pesme, Ja/On kao gramatički i retorski neimenljivo, odsutno/minulo s(r)edište življenja, označivo tek parataksično odelitim, neharmonizovanim iskazima kao njegovim pregnantno verbalizovanim refleksima.

Reč je zapravo o sintaksički disparatnim metaforičkim imenovanjima, koja, kao što plastično pokazuje prvi tercet, zahvaljujući svojim eliptičnim formulacijama osciluju između značenjskog paralelizma (,Plamen, - spržiti gde lek. / Mač, odsecati glave gde kob”) i opozitnosti (,Melem neprebolu”), odnosno paraboličnosti središnjeg distiha (,Stamen bršljanu deblo, / vekovati gde vek”). U drugom, završnom tercetu metaforična parataksa prerasta u paronomaziju (,Zloduh zlu, dobroti verni rob”), te, najzad, u finalni paradoks (,pečali, - sebi, grob i spas”), koji sopstvo odsutnog/(ne više) živog subjekta imenuje kao „pečal”, egzistencijalni jad, muku i bedu zajedno, istodobno ga označavajući slikovito kao ,jamu” bića i njegovo izbavljenje ujedno. 
Nasuprot drugog slavnog „Epitafa” modernog srpskog pesništva, Miljkovićevog, u čijoj se britkoj formulaciji Ja savim jasno subjektivno (samo)imenuje („Ubi me prejaka reč”), postavljajući tako sopstvo u središte iskaza kao neproblematično, a problematizujući, zauzvrat, sam jezik i njegove potencijalne nosioce (Čija - „moja” ili „tuđa reč”?), u epitafskoj pesmi autora „Osame na trgu” raspoznajemo tek eliptično združene i orkestrirane obrise te famozne instance novovekovnog mišljenja kao njen avetinjski i uz to paradoksalni označitelj, u mnogo čemu korespondentan samom protivrečnom duhu modernog doba.

Za razliku od elipse, koja obrubljuje unutarnji, intrinsičan manjak ili verbalno odsustvo, aluzija dočarava spoljni, ekstrinsičan deficit kazanoga, ono što se priziva i evocira pesničkom rečju. Eliptičnost, drugačije rečeno, dejstvuje prvenstveno u internom kontekstu pesme, dok se dejstvo aluzije po pravilu ostvaruje u eksternim kontekstualnim relacijama, bilo da je reč o samoj književnosti (intertekstualnost), kulturi (intermedijalnost) ili pak o tzv. objektivnoj stvarnosti.

Ono što je ipak zajedničko ovim dvema figurama/postupcima jeste omeđenost, relativna dijagnostičnost verbalno odsutnog, netrasparentnog i/ili nagoveštenog sadržaja. To što je samo latentno prisutno, indikovano pojedinim iskazima ili celim tekstom pesme moguće je identifikovati, ako ne bez ostatka i do poslednje semantičke nijanse, jer priroda poetskog jezika to najčešće ne dozvoljava, onda bar u opsegu koji daje mogućnost suvislog i pertinentnog razumevanja, odnosno tumačenja pesme s obzirom na to što nedostaje.

Jedna sasvim kratka pesma Aleksandra Ristovića pod nazivom „Nova radost” otkriće nam kako „radi” lirska aluzija, pokazujući prikriveni „mehanizam” svog tekstualnog dejstva:

Tek ponešto upamtio sam od onog što čitao sam te večeri. Pa našto čitanje tolikih stranica, i to pri sjaju četiri svetiljke? No, evo tebe gde ideš prema meni noseći malen ljuljan u ruci, bosa, tek u papučama, i on me podseti na sjaj drugih slika. I radost čitanja ispuni me opet.

O čitanju je, dakle, reč, ali takođe i o onome što prati i okružuje to čitanje. Izgleda pri tome logično da je radost iz naslova ista ona „radost čitanja” koja se imenuje u poslednjem stihu pesme. No koja je to zapravo i kakva je to radost kojom je tekst opervažen s početka i završetka? Lako je uvideti da pesma donosi značajnu promenu u doživljaju čitanja kao mentalne aktivnosti s početka, na kojem lirski 
akter obelodanjuje da je „tek ponešto upamtio” od onoga što je čitao, pitajući se potom ,[N]ašto / čitanje tolikih stranica?”. Čini se, prema tome, da je to početno čitanje obeleženo rasejanošću i nedostatkom pažnje koji se pojavljuju kao simptomi verovatnog gubitka čitalačkog zadovoljstva i motivacije.

Obrt donosi ženska figura koja u oskudnu lirsku scenografiju pesme ulazi „noseći malen / ljuljan u ruci, bosa, tek u papučama”, jer posle toga sledi završna, takoreći epifanijska spoznaja iskaznog subjekta o tome da ga je „opet”, kako kaže, ispunila izgubljena „radost čitanja”. Pre te objave on, gotovo uzgred, kazuje i to da ga je ljiljan u ruci ženske osobe ,podseti[o] na sjaj drugih slika”. I baš ta opaska predstavlja, verujemo, interpretativni ključ pesme koji otključava zagonetku promene što je dočarana u svega osam stihova Ristovićevog sugestivnog lirskog ostvarenja.

Ali koje su i kakve su te enigmatične „druge” slike, koje prate pojavu žene s ljiljanom u ruci? Razložno je pretpostaviti da je reč o kvalitativnoj drugosti, kao što je razložno zaključiti - budući da ne postoji drugačiji tekstualni nagovešaj - da podrazumevane „prve” slike predstavljaju ono što lirsko Ja u datoj situaciji i doslovno vidi kao najvažniji sadržaj u minimalistički svedenom svetu pesme. Izgleda, dakle, da Ristovićevi stihovi oblikuju svojevrstan efekat ,slike u slici”, i to tako što neposredno, čulno doživljene stvarnosne predstave u pamćenje lirskog aktera prizivaju „sjaj” kvalitativno drugačijih, ne-čulnih i ne-stvarnosnih, u izvesnom smislu drugostepenih slika, moglo bi možda da se kaže.

Čini se pri tome da nas ukupni štimung ove kratke pesme vodi prema imaginiranju ,starinskog”, drevnog i/ili izvornog okruženja kao konteksta u kojem se pojavljuje misao o tim naknadno evociranim slikama. Kad se pita ,našto / čitanje tolikih stranica, i to / pri sjaju četiri svetiljke?" lirsko Ja, naime, ne izražava samo sumnju u svrhovitost „,sholastičkog” bavljenja knjigama, istim stihovima ono ocrtava i kognitivne obrise svog svedenog sveta, koji teško može biti podneblje modernog ili savremenog sveta, budući da se u njemu još uvek čita pod svetlošću lampe.

Otuda i prizivanje „drugih slika" u kontekstu same pesme najverovatnije predstavlja evokaciju starije imaginativne tradicije, i to one intertekstualne, biblijske provenijencije. Pojava ženske figure „tek u papučama” i s ljiljanom u ruci po svemu sudeći, naime, predstavlja moguću aluziju na starozavetnu „Pesmu nad pesmama”, jedan od kulturno najprominentnijih tekstova iz Svetog pisma koji svoju popularnost duguje izrazitoj poetskoj vokaciji i osobenom tretmanu erotske tematike, nekarakterističnom za kanonski priznatu teološku literaturu (vidi npr. Kingsmill, 2009). 
U središtu ovog aluzivnog prizivanja nalazi se simbolika ljiljana, cveta koji je tradicijski gledano najčešće dovođen u vezu s čistotom i čednošću, pa stoga, primerice, u likovnoj imaginaciji predstavlja skoro neizostavan atribut Deve Marije (vidi npr. Cirlot, 2001: 188-189). Najznačajnije simbolično pojavljivanje ljiljana u judeohrišćanskoj tradiciji ipak predstavlja Solomonova čuvena pesma koja na upečatljiv način slavi erotsku ljubav i njeno združeno, puteno i duhovno dejstvo. „Ja sam ruža saronska, ljiljan u dolu”, veli već na početku „crna, ali lijepa” dragana, čiji ljubljeni na to odmah u sledećem stihu uzvraća u istom tonu: „Što je ljiljan među trnjem, to je draga moja među djevojkama" (2: 1-2), da bi potom erotska simboličnost postala još naglašenija i putenija (,Dvije su ti dojke kao dva laneta blizanca, koja pasu među ljiljanima”, 4: 5; „Obrazi su mu kao lijehe mirisnoga bilja, kao cvijeće mirisno; usne su mu kao ljiljan, s njih kaplje smirna žitka”, 5: 13; „Ja sam dragoga svojega, i moj je dragi moj, koji pase među ljiljanima”, 6: 2; „Trbuh ti je kao stog pšenice ograđen ljiljanima”, 7: 2).

Tako ljiljan ovde postaje svojevrsna simbolička „moneta”, „licem” okrenuta prema stihovima i njihovom čitanju, a „naličjem” prema aluzivnom podtekstu i razumevanju iskazne zagonetke pesme. Još od antičkog doba teorija razlikuje dva bazična tipa tekstualne aluzije, imitatio i aemulatio, tj. skrupulozno oponašanje najboljih svojstava odabranog teksta/modela i pokušaj prevladavanja uzora na neki način, poboljšanjem ili pak nadograđivanjem onoga na šta se aludira (vidi Van Tress, 2004: 7-8). Moderna književnost nesumnjivo je, zbog svoje ukupne dispozicije, naklonjenija aemulatio modusu, i to u onom vidu koji se bliže označava kao oppositio in imitando, što podrazumeva aludiranje motivisano potrebom izražavanja vlastitog stava ili viđenja (12), odnosno upotrebu refleksivne aluzije, koja, za razliku od integrativne, okrenute harmonizaciji predloška i njegove asocijacije, teži dijalogu (inter)tekstualnih ,glasova” uključenih u aluzivnu relaciju (17).

Smisao intertekstualne aluzije u Ristovićevoj pesmi, koja jednostavnim imenovanjem simbolički poznatog entiteta aktivira kulturno pamćenje i aktuelizuje povlašćeno značenje, ne leži, očevidno, tek u eruditnom podsećanju na civilizacijski oglašenu tradiciju. Tekstualna činjenica da je taj entitet ovde doveden u vezu s takođe aluzivnim prisustvom erotske aficiranosti (sugerisana, no neeksplicirana obnaženost, i ujedno nagoveštena čednost ženskog aktera) u prvi plan tumačenja stavlja, čini se, kontekstualnu upotrebu kulturnog/literarnog znanja o kojem je reč, a koje ovde rezonuje kompleksno i refleksivno, dakle dijaloški, vraćajući na završetku postupka čitalačku pažnju upravo na znanje i kulturu kao takvo, ali pri tome računa i na svest o aktuelnom/modernom gledanju na stvari. 
Stoga aluzivnost ovde u krajnjoj liniji služi implicitnom intertekstualnom dijalogu, u okviru kojeg evokacija kulturno subverzivnih semantičkih potencijala „Pesme nad pesmama” vodi suspenziji „knjiški” inertnog shvatanja književnosti i kulture i ponovnom otkrivanju životvornosti čitanja, koje nam u sadejstvu s onim što čitanje prati i okružuje, u krajnjem ishodu može doneti obnovu onog prvotnog i izvornog oduševljenja s kojim smo mu nekad pristupali, tražeći u knjigama lično doživljeno iskustvo i otkrovenje egzistencijalnih spoznaja kao ovde i sada prosvetljujućih za nas. Upravo to se, naime, događa iskaznom akteru Ristovićeve pesme, čiji naslov - u obrtu kojeg, valja primetiti, kao takvog nema u Solomonovoj pesmi - odista objavljuje novu radost kao ponovno otkriće vitalne veze između književnosti, odnosno kulture i života samog, što čitanje reafirmiše kao izraz čiste ljubavi i takoreći biblijski čedne strasti prema obe ove, često odvojene sfere egzistencije u njihovom beskrajnom ogledanju i pretapanju (vidi Ferber, 2007: 117).

Tako se najposle aluzija otkriva kao dvoguba, intratekstualno i ekstratekstualno realizovana figura u samom „srcu” Ristovićeve poetske vizije. Ono, naime, što privlači lirskog aktera „Nove radosti” kao nejasno ali neodoljivo prisećanje ujedno je i ono što vodi njenog čitaoca, upravljajući njegovom željom da pronađe tek ovlaš nagovešteno ishodište središnje situacije pesme, sravnjujući i stavljajući jednu naspram drugoga pri tome umetnost i stvarnost, književnost i život.

Aluzija možda i jeste upravo to - umeće vrhunskog zavođenja, lelujavo obećanje koje daje verbalne nagoveštaje i obrise, ali ne i sam neuhvatljivi predmet žudnje, mameći tom neprestanom sedukcijom na tananu igru iskušavanja i prepoznavanja što nas, umesto konačnog i potpunog osvajanja, naposletku suočava sa značenjem vlastite želje. A ona polazi od čitalačkog podstreka, pa ide iznad i preko njega, prizivajući u pomoć naše sopstveno iskustvo življenja među ljudima, da bi se najzad vratila tekstu, ogledajući se i preispitujući ponovo u njegovoj stabilno-nestabilnoj izazovnosti, koja aluzijom ispostavlja ,imaginativni zahtev čitaocu, ostavljajući njemu ili njoj prostor imaginativne spekulacije" (Whitworth, 2010: 86). Klaudio Giljen čak misli da, u celini gledano, ,[k]njiževno delo čine eksplicitan iskaz i aluzivna forma”, pri čemu ,[j]edna od osnovnih vrlina 'stila' nekog pisca - a pod stilom obično razumemo vidljivi deo ledene sante - počiva u podobnosti eksplicitnih iskaza o kojima je reč aluzivnim formama" (Giljen, 1982: 239).

Aluzivna forma ne mora, međutim, nužno i uvek da ima prepoznatljivo, za detekciju prijemčivo značenje, čak ni onda kad aluzija zavodi neodoljivo i 
neotklonjivo. Izvrstan primer pronalazimo u „Livadi” Stevana Raičkovića, pesmi koja na prvi pogled donosi lirsku osećajnost gotovo poslovično raspoznatljivu u opusu ovog pesnika, ali ispod toga zapravo skriva iznenađenje:

U ovoj livadi poznajem ja već mnoge vlati.

Juče je ova, u suton, bila travka svijena.

Sad ima žute ivice i suve kad ih dirnem.

Kad gledam iz daljine u zeleno: ona se sama zlati.

Iznad usana mi je već miris sena:

Sutra ću i druge izbrojati.

U ovoj livadi do žbuna ima devet mravinjaka.

Prođem i gurnem nogom a zemlja se zacrni.

Onda podignem glavu i gledam igru oblaka.

Ja znam kolika je livada:

Kada se raskoračim pređem je u dvanaest koraka.

$\mathrm{Na}$ žbun mogu da stanu tri ptice najviše.

Kad pođem prema njemu: prvo jedna poleti.

Pogledam za njom u nebo:

I dve se izgubiše.

Onda razbijam glavu na šta me to podseti.

I najbolje je u suton kad počne mrak da pada:

Onda mi se učini da šapuće livada.

Napregnem uho i slušam.

Meni je sasvim dobro u livadi.

Sednem na vlati

I puna mi je duša.

Prva neobičnost tiče se labavljenja stihovnih uzusa. Iako je Raičković autor sklon i slobodnijoj formi lirskog zapisa, onda kad poseže za vezanim stihom, a to je najčešći slučaj, uglavnom se drži njegovih konvencija. Ovde, međutim, odstupa od njih na dva načina - najpre metrički, jer ne postoji ustaljena mera (stihovi variraju od kratkog do veoma dugog, od peterca do osamnaesterca), a zatim donekle i rimarijski, budući da je rima nepravilna i „neuredna”, kao što može da se primeti (shema rimovanja prvih trinaest stihova: abcabadedfdgh). Ovakvo formalnokonstruktivno ustrojstvo kao da sugeriše i neku vrstu unutrarnjeg disbalansa, kako to već biva kod dobrih pesnika, kod kojih forma $\mathrm{i}$ ono što je formom posredovano nisu slučajni, nego u artističkom smislu zakonomerni saveznici.

I mada „Livada” ima Raičkovićevu takoreći obaveznu lirsku „scenografiju” u vidu prirodnog kutka u kojem se budi emotivno-refleksivna doživljajnost lirskog subjekta, bliži uvid otkriva i ,pukotine” u toj raspoznatljivoj konstelaciji. Postoji, naime, diskrepancija između početnog i završnog impulsa pesme. „I najbolje je u 
suton kad počne mrak da pada: / Onda mi se učini da šapuće livada. / [...] Sednem na vlati / I puna mi je duša" - bez obzira na to što bi u sklopu očekivanja od Raičkovićeve lirske izražajnosti u neku ruku mogla da bude i početna, ova finalna situacija, koja naglašava empatijsku stopljenost s prirodnim okruženjem, zapravo odudara od inicijalne upućenosti na racionalno, takoreći minuciozno meritokratsko (u)poznavanje s njim („U ovoj livadi poznajem ja već mnoge vlati. / [...] Sutra ću i druge izbrojati. [...] Kad se raskoračim pređem je u dvanaest koraka" itd).

Središnji deo pesme donosi potpuni obrt i svojevrsnu negaciju prvobitno izraženog posvećeničkog zanimanja za sve ono što čini prirodu. „U ovoj livadi do žbunja ima devet mravinjaka", kazuje najpre anonimno lirsko Ja u duhu svoje „prirodoslovne” opsesije, da bi odmah potom dodalo „Prođem i gurnem nogom a zemlja se zacrni", demonstrirajući neempatičnost i brutalnost koja u potpunosti protivreči deklarisanom zanimanju za život prirode u svim njenim, pa i najneznatnijim vidovima.

Vrhunac ovog unutarnjeg preokreta predstavljaju stihovi koje zbog njihove važnosti donosimo još jednom:

Na žbun mogu da stanu tri ptice najviše.

Kad pođem prema njemu: prvo jedna poleti.

Pogledam za njom u nebo:

I dve se izgubiše.

Onda razbijam glavu na šta me to podseti.

Nije teško uočiti da je poslednji stih u neku ruku zapravo analogan ključnom stihu iz Ristovićeve "Nove radosti”, u kojem pojava ženske figure s ljiljanom u ruci lirsko Ja ,podseti na sjaj drugih slika”. I ovde je, naime, reč o naporu za prizivanjem onoga što je pohranjeno u pamćenju iskaznog subjekta, a što, u nemogućnosti neposrednog imenovanja, neizbežno prerasta u aluziju. Čini se, međutim, da postoji i kontekstualna razlika između ove dve lirske situacije i njima podstaknute aluzivnosti. Iskazno Ja „Nove radosti” imenuje simbolični „,sjaj drugih slika", koji - videli smo - zahvaljujući celokupnom ambijentu s patinom drevnosti, jednako kao i kulturnoj frekventnosti simbolike ljiljana, upućuje na prihvatljivu mogućnost intertekstualne relacije s biblijskom „Pesmom nad pesmama”. Iskazno Ja „Livade”, s druge strane, umesto simboličnog jezika koristi kolokvijalnu frazeologiju. I upravo ta, nepoetski sročena formulacija „Onda razbijam glavu na šta me to podseti" sred naoko izrazitog poetski intoniranih formulacija mora da zazvuči neprimereno, a to što ona „štrči” upućuje na njen poseban status.

Pomenutu formulaciju valja uzeti kao središte interpretacije, zato što njeno značenje neminovno deluje ,zrakasto” na tekst pesme, utičući na njeno krajnje 
razumevanje i prospektivno i retrospektivno. Ono što je, osim „samopotkazujuće” neprimerenog oblika, čini takvom jeste nemogućnost identifikacije mogućeg sadržaja aluzije koju ona ispostavlja čitaocu. Uprkos očitom prizivanju numeričke simbolike, pomenuta aluzija ostaje, naime, nerealizovana u svesti lirskog Ja, ali isto tako i u čitalačkom razumevanju. Jednostavno kazano, ne postoji kredibilna asocijacija na sadržaj/značenje koje bi bilo razrešenje postavljene nedoumice, ono na šta iskazni akter „aludira” (p)ostaje varka, mentalna opsena bez interpersonalno prihvatljivog korelativa.

Nasuprot intertekstualno ukotvljene i stoga sadržajno „pune” aluzije iz Ristovićeve pesme, ovde se, prema tome, susrećemo s „praznom”, vakantnom aluzijom koja izaziva tzv. izneverena očekivanja, otkrivajući svojom intertekstualnom, odnosno interkulturnom besadržajnošću iskaznu neverodostojnost subjekta, verbalno egzibicionističku i artificijelnu narav njegove opsesije znanjem uopšte, jednako kao i znanjem o prirodi.

U svetlu retrospektivnog uviđanja da i najveći broj drugih iskaza i kvalifikacija u pesmi protivreče njenom deklarativnom tonu, jednako kao i u svetlu uočavanja formalne disharmoničnosti kazivanja, ova samopodrivajuća aluzija postaje nekom vrstom poetičkog i interpretativnog ključa pesme, jer otvara uvid u onu naročitu, ambivalentnu promenu neposredno iskazanog značenja koju po pravilu povezujemo s fenomenom ironije. „Livadu”, stoga, valja čitati i razumeti kao ironijski sklopljenu lirsku tvorevinu, čiji iskazno „dramatizovani” akter kontradiktornom retorikom na neki način diskvalifikuje svoju nominalno proklamovanu poziciju, izrastajući pred čitaočevim očima u verbalno „nepouzdanu” i samopotkazujuću figuru.

Kad smo kazali da Raičkovićevu pesmu valja čitati kao ironijski sklopljenu tvorevinu pri tome, valja naglasiti, nismo imali na umu jednostavan zbir ironičnih iskaza, nego upravo njeno celokupon verbalno ustrojstvo, njenu lirsku strukturu. Pojedinačno uzeti, stihovi i/ili poetski iskazi lirskog Ja, poput onoga o tome da ,do žbunja ima devet mravinjaka” pa kad prođe „gurne[m] nogom i zemlja se zacrni”, ne moraju zvučati ironično; ali kad se uzmu obzir drugi iskazi, koji uokviruju ovaj iskaz i koji odreda sugerišu subjektovo blisko poznavanje i brigu o prirodnom svetu livade, brutalno rušenje mravinjaka dobija obratno-inverzivno, autosuspendujuće i autodiskvalifikujuće značenje.

Kontekst, uzajamno dejstvo sastavnih činilaca i/ili delova teksta, predstavlja ono što u ovom slučaju stvara ironijski učinak, jer u pesmi „kontekst obdaruje neku posebnu reč, sliku ili iskaz značenjem”, a „očitu izmenu iskaza uz pomoć konteksta karakterišemo kao 'ironičnu', primećuje Klint Broks, jedan od prvaka anglo- 
američke „nove kritike”, u svom uticajnom eseju o ironiji kao načelu pesničke strukture (Brooks, 1962: 730). Kontekst je ono što u lirici, zahvaljujući njenoj izrazitoj formalno-semantičkoj organizaciji, ima naglašen značaj, pa „svaki 'iskaz' u pesmi trpi pritisak konteksta i modifikovan je njime" (731).

Baš to je, čini se, na delu u Raičkovićevoj pesmi, koja - od početnih iskaza o „poznavanju”, brojenju i posmatranju svake vlati u livadi, do završnog ignorantskog sedanja na te iste vlati s ,punom” dušom, od rušenja mravinjaka do falsičnog aludiranja na simboliku ptica na žbunu tamo gde samoj prirodi to ništa ne znači i nije potrebno - stvara konstantan pritisak konteksta koji značajno menja, invertuje značenja stihova i slika, proizvodeći ironijsko dejstvo celine kao ono što u svesti čitaoca/tumača u krajnjem ishodu omogućuje njeno valjano, neprotivrečno razumevanje. „Livada” nam tako pokazuje da s drugačijim ishodom u odnosu na elipsu i aluziju, ironija kao strukturni princip služi sličnoj svrsi izražavanja prećutanog i izostavljenog, onoga što upravo kao takvo, tekstualno odsutno, može da ostvari posebno značajan receptivni upliv i efekat.

„Veliki deo moderne poezije koristi ironiju kao posebnu i možda karakterističnu strategiju", s pravom primećuje Klint Bruks (738). U istom duhu, moglo bi se kazati da ironija, to sofistikovano oruđe modifikacije i promene značenja s dalekosežnim dejstvom, predstavlja povlašćeno sredstvo moderne književnosti uopšte, njenu takoreći univerzalnu poetičku i smislotvornu podlogu.

Naspram intrinsičnog manjka elipse i ekstrinsičnog deficita aluzije, koje verbalno nagovešavaju i sugerišu ono što je iz teksta izostavljeno ,iznutra” ili mu nedostaje „spolja”, ironija je, moglo bi možda da se kaže, intrinsično-ekstrinsična; ona nije puki semantički prevrat ili inverzija izrečenog $u$ neizrečeno, zato što i jedno i drugo, transparentno i latentno, predstavljaju njene kompatibilne, ravnopravno egzistentne činioce. Kad shvatimo na šta ciljaju elipsa i aluzija, makar nakratko moženo da zaboravimo na njih i okrenemo se onome što smo semantički dokučili, tražeći mu mesto u okviru semantičkog mozaika petpostavljene/zamišljene celine. Dejstvo ironije teško da, s druge s trane, postoji mimo njenog titrajućereverzibilnog, dvo-smislenog oscilovanja između kazanog i nekazanog, onoga što je „u” tekstu, i onoga što je „,van” teksta, s njegove iskazno „nevidljive” strane, ali je i te kako neophodno da bi se on razumeo bez nepremostivih kontradikcija.

„S tačke gledišta tumača, ironija je interpretativni i intencionalni postupak: to je stvaranje ili pripisivanje značenja, dodatnog ili drugačijeg u odnosu na ono što je iskazano, zajedno sa stavom i prema rečenom i prema nerečenom”, umesno primećuje Linda Hačn u svojoj inspirativnoj i instruktivnoj studiji o „teoriji i politici” ironije (Hutcheon 1995: 11). Bilo da je reč o pojedinačnom iskazu/izrazu, 
ili celom tekstu, ironija, dakle, postoji kao dinamično-reverzibilno dvojstvo, čijom je nesvodivom proizvodnjom značenja ova zaista osobena figura/prosede verovatno i zavredila svoje široko prisustvo u modernoj i savremenoj književnosti.

Skupa s aluzijom i elipsom, ova takoreći sveprisutna figura, odnosno prosede, čini pak provizorno retorsko trojstvo koje inventivnim upošljavanjem intrinsično-ekstrinsičnih vidova verbalnog uskraćivanja nudi semantički produktivne mogućnosti, otvarajući široku lepezu pesničkog kazivanja. Na taj način sugestija prećutanog postaje jedan od konstitutivnih i bitnih činilaca modernog pesničkog izraza, u mnogo čemu komplementaran verbalno ekspliciranim aspektima saopštavanja, a neretko i nadređen njima u svetlu poetičkih strategija svojstvenih epohalnom afinitetu prema intratekstualnoj $\mathrm{i} / \mathrm{ili}$ ekstratekstualnoj dijalogičnosti s traidicijom i savremenošću. Stoga i interpretativni potencijali elipse, aluzije $\mathrm{i}$ ironije $\mathrm{u}$ polju heremeneutičkog tretmana imaju $\mathrm{u}$ izvesnom smislu povlašćeno mesto, u skladu $\mathrm{s}$ kompleksnošću izražajnih afiniteta moderne i savremene poezije.

Tihomir Brajović

THE FUNCTION OF ELLIPSIS, ALLUSION AND IRONY IN THE INTERPRETATION OF LYRIC

\section{Summary}

Starting from the assumption of the significance of verbal omission in the artistic literature this paper is based on the study of interpretative function of ellipsis, allusion and irony in lyrical poetry. Relying on relevant theoretical sources (C. Brooks, K. Guillen, L. Hutcheon, A. William, P. de Man, S. Newstok, H. Van Tress etc.) the paper considers these concepts both as rhetorical figures and structural procedures. Ellipsis is here theoretically considered as intrinsic deficiency, allusion as extrinsic deficinecy, and irony as intrinsic-extrinsic deficiency of possible verbal content. Special attention is paid to (non)verbal context and it's semantic influence as a widespread discursive tool in modern literature and art. As explicative examples the autor took poems of several promminent modern Serbian poets (M. Nastasijevic, S. Raickovic, A. Ristovic). At the end of the paper, the author exposes the theoretical and metodological cosequences of his study.

Keywords: poetics, rhetorics, ellipsis, allusion, irony, intrinsicity, extrinsicity, context 


\section{LITERATURA}

Allen, W. (2007). Ellipsis: Of Poetry and the Experince of Language after Heideger, Hölderlin, and Blanchot. Albany: State University of New York Press.

Brooks, C. (1962). „Irony as a Principle of Structure”. Literary Opinion in America. Morton Dauwen Zabel (ed.). New York: Harper \& Row. 729-741.

Cirlot, J. E. (2001). A Dictionary of Symbols. London: Routledge.

De Man, P. (1984). The Rhetoric of Romanticism. New York: Columbia University Press.

Ferber, M. (2007). A Dictionary of Literary Symbols. Cambridge: Cambridge University Press.

Giljen, Klaudio (1982). „Stilistika tišine”. Književnost kao sistem: Ogledi o teoriji književne istorije. Nolit: Beograd. 201-250.

Hutcheon, L. (1995). Irony's Edge: The theory and politics of irony. London and New York: Routledge.

Kingsmill, E. (2009). The Song of Songs and the Eros of God: A Study in Biblical Intertextuality. Oxford - New York: Oxford University Press.

Mendel, Oscar (1998): Fundamentals of the Art of Poetry. Sheffield Academic Press: Sheffield.

Настасијевић, М. (1971). Песме, приповетке, драме, Нови Сад - Београд: Матица српска - Српска књижевна задруга.

Newstok, S. (2009). Quoting Death in Early Modern England: The Poetics of Epitaphs Beyond the Tomb. New York: Palgrave Macmillan.

Петковић, Н. (2003). „Чему служи стилистика“. Публицистичка стилистика (хрестоматија). Српско Сарајево: Завод за уџбенике и наставна средства. 5-42.

Раичковић, С. (1972). Песме, Нови Сад: Матица српска.

Ристовић, А. (1995). Мириси и гласови: Изабране песме. Београд: Српска књижевна задруга.

Staiger, Emil (1963): Grundbegriffe der Poetik. Atlantis Verlag: Zürich.

Užarević, Josip (1991): Kompozicija lirske pjesme (O. Mandeljštam i B. Pasternak). Zavod za znanost o književnosti Filozofskog fakulteta u Zagrebu: Zagreb.

Van Tress, H. (2004). Poetic Memory: Allusion in the Poetry of Callimachus and the 'Metamorphoses' of Ovid. Leiden - Boston: Brill.

Whitworth, M. (2010). Reading Modernist Poetry. Malden - Oxford: WileyBlackwell. 
Wolf, Werner (2005): „The Lyric: Problems of Definition and a Proposal for Reconceptualisation”. Eva Müller-Zettelmann and Margarete rubik (ed.): Theory into Poetry: New Approaches to the Lyric. Rodopi: Amsterdam New York. pp. 21-56. 